\section{(6) OPEN ACCESS}

\title{
Micro-fragmented adipose tissue for treatment of knee osteoarthritis with Baker's cyst: a case study
}

\author{
Jennifer R Arthurs, ${ }_{1}^{1}$ Cheryl M Desmond, ${ }^{1}$ Sarvam P TerKonda, ${ }^{2}$ Shane A Shapiro ${ }^{3}$
}

'Department of Regenerative Medicine, Mayo Clinic, Jacksonville, Florida, USA ${ }^{2}$ Department of Plastic Surgery, Mayo Clinic, Jacksonville, Florida, USA

${ }^{3}$ Department of Orthopedic Surgery, Mayo Clinic, Jacksonville, Florida, USA

\section{Correspondence to} Mrs Jennifer R Arthurs, arthurs.jennifer@mayo.edu

Accepted 5 May 2018

\section{SUMMARY}

Adipose-derived therapies have increased in popularity for treatment of painful orthopaedic conditions, such as osteoarthritis. We report the passage of fat into a Baker's cyst after injection of micro-fragmented adipose tissue in a patient with bilateral knee arthritis. Following fat grafting, the patient required drainage of fatty fluid from within the Baker's cyst on multiple occasions. Approximately 3 months postprocedure, she began to notice an improvement in her knee pain with no further recurrence of pain or swelling from her Baker's cyst.

\section{BACKGROUND}

Osteoarthritis (OA) of the knee is one of the most common joints affected by joint degeneration. Although OA is a biomechanical process involving slow deterioration of the articular cartilage, there is also a biochemical process that mediates the pathological changes within the joint. Treatment for knee osteoarthritis primarily focuses on symptom control, with knee replacement as alternative when those interventions are unsuccessful. Current recommendations from the American Academy of Orthopaedic Surgeons for treatment of arthritis include weight loss for body mass index greater than 25 , physical therapy, gentle pain relievers and occasional steroid injections. ${ }^{1}$ There have been recent developments involving the use of novel therapies to treat $\mathrm{OA}$, some involving the use of human

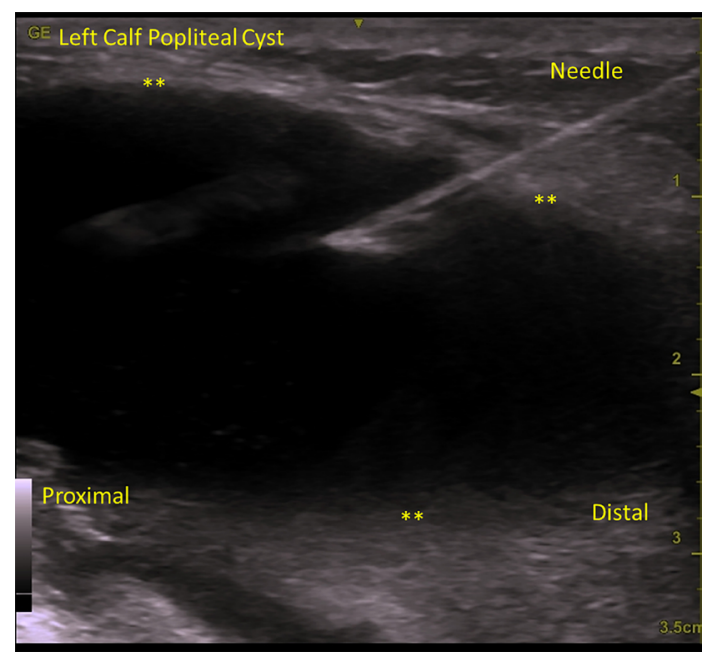

Figure 1 Aspiration of symptomatic multiloculated Baker's cyst on the left knee using ultrasound guidance; approximately $40 \mathrm{~mL}$ of synovial fluid was aspirated. cells and tissues, both autologous and allogeneic. Such cell-based therapies have been shown to have osteogenic and chondrogenic potential and thus theoretical promise for treatment of degenerative joint disease. Other therapies such as platelet-rich plasma and fat grafting employ extracellular modalities to treat joint pain. Several studies have been published detailing possible mechanisms whereby such cell-based and extracellular treatments induce therapeutic responses by immunomodulatory, paracrine and trophic pathways. ${ }^{2-4}$ The adipose tissue is a desirable source of mesenchymal stromal cells (MSCs) due to large quantities of MSCs, tissue abundance and feasibility in collection. ${ }^{56}$ Because of theoretical regenerative capacity and potential to mediate the biochemical process associated with OA, adipose-derived cell procedures have become increasingly popular for orthopaedic conditions such as OA. ${ }^{7-12}$ Therapies using adipose tissue to treat OA include simple fat transfer, enzymatically digested stromal vascular fraction containing MSCs and culture-expanded adipose-derived stem cells. Micro-fragmented devices are commercially available and are approved by the Food and Drug Administration for use in fat grafting in orthopaedics, but little has been studied with respect to outcomes or complications. Nevertheless, such minimally invasive surgical procedures are increasingly being used to treat joint pain from degenerative joint disease. We report an unusual finding after injection of micro-fragmented adipose tissue into a patient with bilateral knee OA and Baker's cyst.

\section{CASE PRESENTATION}

A 65-year-old woman with a history of bilateral knee OA and a symptomatic Baker's cyst of the left knee presented for treatment. The Baker's cyst had required prior ultrasound-guided drainage on more than one occasion. She had previously used standard, conservative therapies for OA, including physical therapy, anti-inflammatories, as well as corticosteroid and hyaluronic acid. Over time, these were of declining benefit. The patient sought alternative pain-relieving treatment strategies and elected to proceed with micro-fragmented lipoaspirate injection of her bilateral knees as part of a concomitant abdominoplasty, using a proprietary, commercially available closed loop sterile collection and processing system. Preoperatively, on the day prior to her procedure, approximately $40 \mathrm{~mL}$ of synovial fluid was aspirated from a symptomatic multiloculated Baker's cyst on her left knee using ultrasound guidance. The aspiration was 
uncomplicated and helped relieve pain and swelling in the popliteal fossa as it had for her in the past (figure 1).

On the day of the procedure, the patient was positioned supine and was under general anaesthesia as part of a concomitant abdominoplasty. She was prepped and draped in the usual fashion. The bilateral knees were exposed and prepped. Relevant landmarks of the abdomen and flank were demarcated bilaterally. An 11 blade scalpel stab wound incision to puncture the skin was performed on each side. Harvest of the adipose tissue was performed using a blunt-tipped 14-gauge cannula (Wells Johnson Infiltration System and Cannula) to infuse a solution of normal saline, lidocaine and epinephrine in a fan-shaped fashion. Once satisfactory tumescence was achieved, the solution was allowed to set within the adipose tissue for $15 \mathrm{~min}$.

A $20 \mathrm{~mL}$ VacLock syringe attached to an 11-gauge lipoaspiration needle was subsequently used in a fan-shaped fashion to aspirate a total of $200 \mathrm{~mL}$ combined adipose tissue and tumescent solution under sterile condition. The resulting product was subsequently transferred to an additional sterile syringe for transfer to a disposable sterile kit, where it was processed mechanically with sterile saline and mechanical bearings, producing approximately $14 \mathrm{~mL}$ of micronised nanofat to be injected into the affected knees.

The left knee was sterilely prepped and draped. Under continuous ultrasound guidance, using sterile technique, the suprapatellar pouch was identified in the anterior distal thigh deep to the quadriceps tendon. One percent lidocaine without epinephrine was used to anaesthetise the skin and subcutaneous tissue. At a frequency of $10 \mathrm{MHz}$, using an 18-gauge needle, $2 \mathrm{~mL}$ of synovial fluid was aspirated. Seven millilitres of the micro-fragmented adipose product were subsequently injected into the suprapatellar pouch of the knee under ultrasound guidance with the needle in plane.

The procedure was subsequently repeated on the contralateral side, although no fluid was present on the right knee, and therefore no synovial fluid aspiration was performed. There were no complications during the surgical procedure. A sterile dressing was applied. Both the harvest site and the patient's injection sites were bandaged. The patient was instructed on standard postprocedure protocol.

\section{OUTCOME AND FOLLOW-UP}

Approximately 1 week following her procedure, the patient reported worsening swelling of both her knees and calves bilaterally with associated discomfort. Her physical examination demonstrated good range of motion, and normal motor bulk, tone and stability with evidence of a small effusion, but no erythema or warmth. Her calf was swollen and tender bilaterally, but duplex ultrasound examinations were negative for deep venous thrombosis. Diagnostic musculoskeletal ultrasound revealed evidence of large, complex, multiloculated Baker's cysts with mixed areas of anechoic and hyperechoic signals within the cyst. The hyperechoic regions were well defined and had the appearance of adipose tissue inside the hypertrophied cyst walls. A long-axis view of the cyst demonstrated ballotable fat graft contained within the cyst walls (videos 1 and 2). Figure 2 depicts the right knee Baker's cyst in sonographic long axis, and figure 3 shows the left knee Baker's cyst in short axis with evidence of fat graft within the cyst.

Under ultrasound guidance, approximately $25 \mathrm{~mL}$ of serosanguinous and fatty fluid was removed from the left Baker's cyst. Figure 4 shows an image of the aspirate, a combination of straw-coloured synovial fluid and blood-tinged, fatty

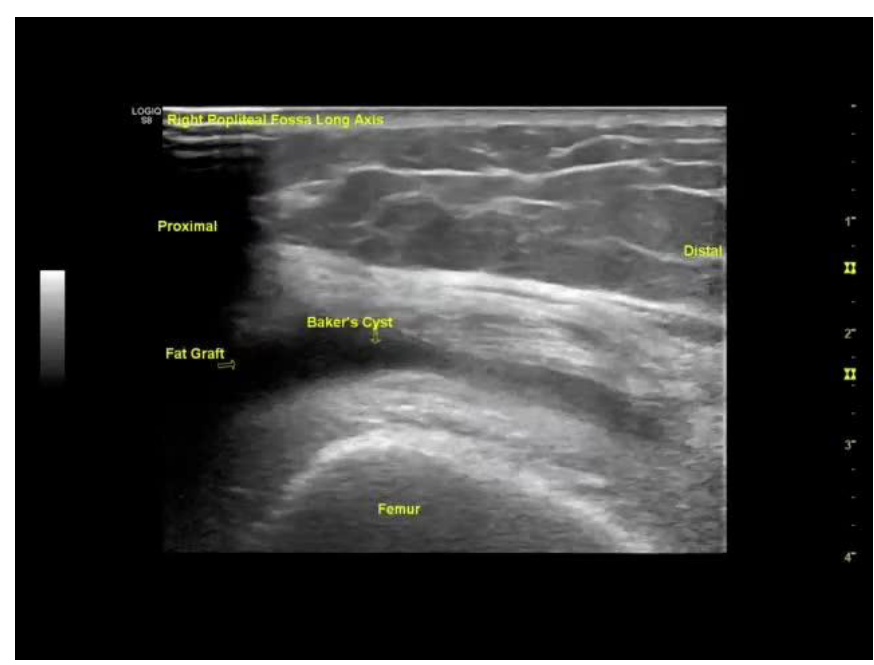

Video 1 Long-axis view of the cyst with ballotable fat graft contained within the cyst walls.

micro-fragmented adipose tissue. Eight millilitres of similar aspirate were recovered from the right knee. The patient reported an improvement in her symptoms for approximately 1 week, followed by recurrence of swelling and pain bilaterally. On repeat sonogram, she continued to have evidence of fat graft within her bilateral Baker's cysts, and subsequently 15 and $10 \mathrm{~mL}$ of serosanguinous fluid were aspirated from the left and right knees, respectively. The patient once again did well for 1 week, with recurrence only in the left leg while the right knee had dramatically improved. An additional $15 \mathrm{~mL}$ of fluid was once again removed from her left knee with persistent evidence of fat graft within her Baker's cyst, although some overall decrease in the appearance. The patient was re-examined 8 weeks post fat graft with only $5 \mathrm{~mL}$ of fluid aspirated for her left knee. At her 12-week follow-up, she reported an overall improvement in her knee pain and function without any additional symptoms from her Baker's cyst.

\section{DISCUSSION}

Novel interventional procedures are continually being attempted to ameliorate pain and symptoms from OA. Early attempts at fat grafting show some initial promise. ${ }^{6}{ }^{13}$ Current thinking

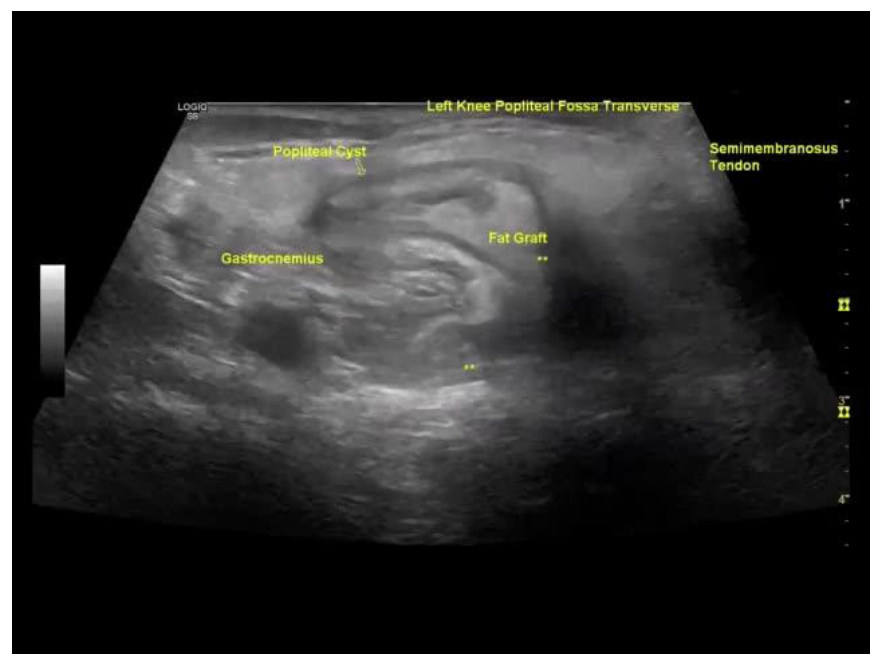

Video 2 Long-axis view of the cyst with ballotable fat graft contained within the cyst walls. 


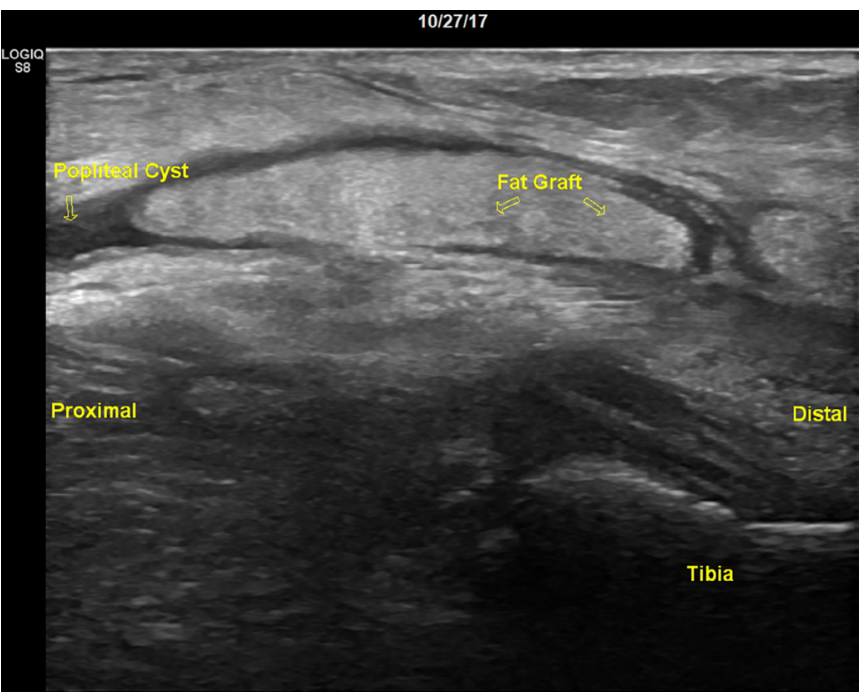

Figure 2 Right knee Baker's cyst in sonographic long-axis view.

regarding the efficacy of a fat transfer procedure lies both in a theoretical biochemical amelioration of the arthritic intrasynovial environment along with any additional biomechanical benefit from the graft material itself. Such theoretical mechanisms of action would presume the graft to be most beneficial when retained within the joint itself.

A popliteal cyst, commonly referred to as the Baker's cyst, is a distention of synovial fluid into the posterior aspect of the knee joint capsule associated with an overproduction of synovial joint fluid. ${ }^{14} \mathrm{~A}$ weakening of the joint capsule at the gastrocnemius and semimembranosus bursa can allow communication between the joint and bursa. ${ }^{15}$ Some patients with Baker's cysts can be asymptomatic, while others experience knee pain and swelling. Drainage of excess synovial fluid for symptomatic relief is sometimes performed. ${ }^{14}$ The prevalence of Baker's cysts is not well known in OA, although the use of ultrasound has simplified its evaluation and diagnosis. ${ }^{16}$ The authors theorise the preprocedural presence of a popliteal cyst allowed for the passage of the fat graft directly from the suprapatellar pouch into the cyst. Additionally, not only might a passage of the graft from the suprapatellar pouch into the popliteal cyst blunt the beneficial response of the graft in the knee joint, but quite possibly cause pain in the popliteal fossa and calf as well. More investigation into the effects of such procedures is warranted in those patients who might be at risk for recurrent popliteal cysts.

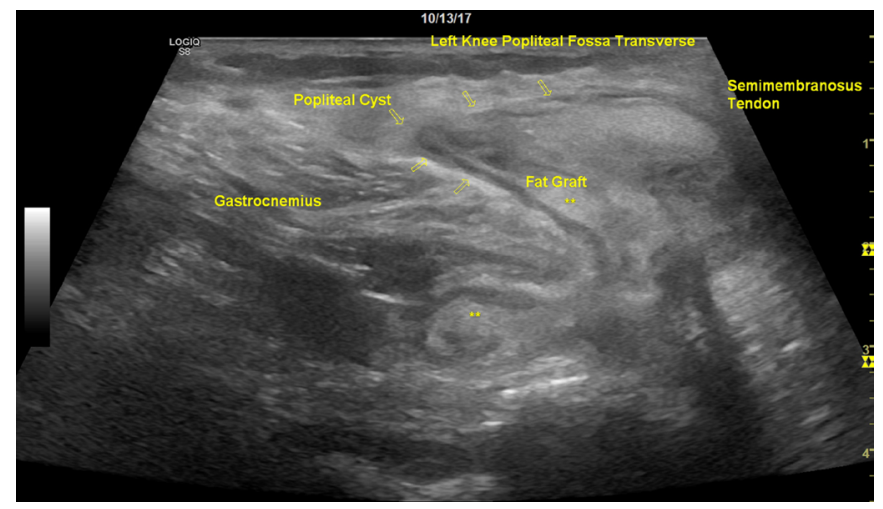

Figure 3 Left knee Baker's cyst in short axis with evidence of fat graft within the cyst.

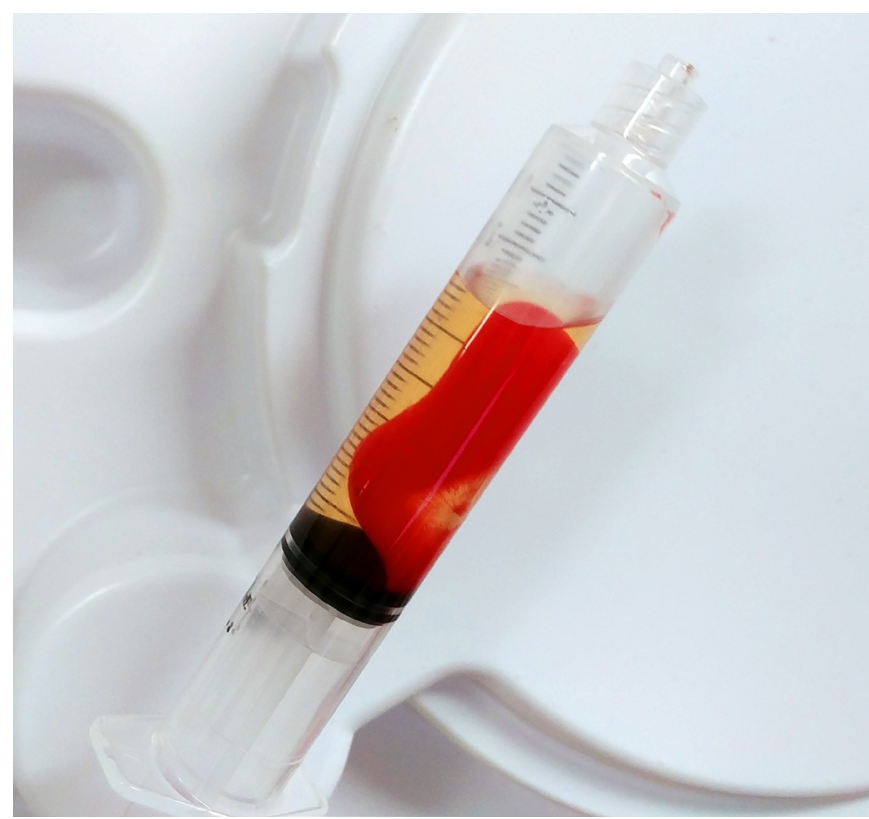

Figure 4 Image of the Baker's cyst aspirate, a combination of strawcoloured synovial fluid and blood-tinged, fatty micro-fragmented adipose tissue.

\section{Learning points}

- While adipose cell-based therapies are increasingly available for treatment of orthopaedic conditions, there has been little reported with regard to outcomes or complications.

- Patients with knee osteoarthritis can develop Baker's cysts, although the prevalence is not well studied.

- We describe a case in which adipose tissue travelled from the suprapatellar pouch into a Baker's cyst, requiring drainage for symptomatic relief.

- Providers may wish to make a preprocedural survey of the popliteal fossa for presence of Baker's cysts and exercise caution when choosing a fat grafting procedure into the affected knee.

Contributors JRA: data collection, drafting the article, critical revision of the article and final approval of the version to be published. CMD: data collection and final approval of the version to be published. SPTK: conception or design of the work, data collection, data analysis and interpretation, critical revision of the article, and final approval of the version to be published. SAS: conception or design of the work, data collection, drafting the article, data analysis and interpretation, critical revision of the article, and final approval of the version to be published.

Funding The authors have not declared a specific grant for this research from any funding agency in the public, commercial or not-for-profit sectors.

Competing interests None declared.

Patient consent Obtained.

Provenance and peer review Not commissioned; externally peer reviewed.

Open Access This is an Open Access article distributed in accordance with the Creative Commons Attribution Non Commercial (CC BY-NC 4.0) license, which permits others to distribute, remix, adapt, build upon this work non-commercially, and license their derivative works on different terms, provided the original work is properly cited and the use is non-commercial. See: http://creativecommons.org/ licenses/by-nc/4.0/

(C) BMJ Publishing Group Ltd (unless otherwise stated in the text of the article) 2018. All rights reserved. No commercial use is permitted unless otherwise expressly granted. 


\section{Novel treatment (new drug/intervention; established drug/procedure in new situation)}

\section{REFERENCES}

1 American Academy of Orthopaedic Surgeons. Treatment of osteoarthritis of the knee: Evidence-based guidelines. 2nd edition, 2013. Available from. https://www.aaos.org/ cc_files/aaosorg/research/guidelines/treatmentofosteoarthritisofthekneeguideline.pdf.

2 Caplan Al. Mesenchymal stem cells: Time to change the name! Stem cells transl med. 2017:6:1445-51.

3 Hernigou P, Trousselier M, Roubineau F, et al. Stem cell therapy for the treatment of hip osteonecrosis: A 30-year review of progress. Clin Orthop Surg 2016;8:1-8.

4 Madry H, Gao L, Eichler H, et al. Bone marrow aspirate concentrate-enhanced marrow stimulation of chondral defects. Stem Cells Int 2017:2017:1-13.

5 Bianchi F, Maioli M, Leonardi E, et al. A new nonenzymatic method and device to obtain a fat tissue derivative highly enriched in pericyte-like elements by mild mechanical forces from human lipoaspirates. Cell Transplant 2013;22:2063-77.

6 Tremolada C, Colombo V, Ventura C. Adipose tissue and mesenchymal stem cells: State of the art and lipogems $®$ technology development. Curr Stem Cell Rep 2016;2:304-12.

7 Kim YS, Choi YJ, Koh YG. Mesenchymal stem cell implantation in knee osteoarthritis: an assessment of the factors influencing clinical outcomes. Am J Sports Med 2015:43:2293-301.

8 Kim YS, Choi YJ, Lee SW, et al. Assessment of clinical and MRI outcomes after mesenchymal stem cell implantation in patients with knee osteoarthritis: a prospective study. Osteoarthritis Cartilage 2016;24:237-45.
9 Kim YS, Choi YJ, Suh DS, et al. Mesenchymal stem cell implantation in osteoarthritic knees: is fibrin glue effective as a scaffold? Am J Sports Med 2015;43:176-85.

10 Kim YS, Kwon OR, Choi YJ, et al. Comparative matched-pair analysis of the injection versus implantation of mesenchymal stem cells for knee osteoarthritis. Am J Sports Med 2015;43:2738-46.

11 Koh YG, Choi YJ, Kwon SK, et al. Clinical results and second-look arthroscopic findings after treatment with adipose-derived stem cells for knee osteoarthritis. Knee Surg Sports Traumatol Arthrosc 2015;23:1308-16.

12 Koh YG, Jo SB, Kwon OR, et al. Mesenchymal stem cell injections improve symptoms of knee osteoarthritis. Arthroscopy 2013:29:748-55.

13 Russo A, Condello V, Madonna V, et al. Autologous and micro-fragmented adipose tissue for the treatment of diffuse degenerative knee osteoarthritis. J Exp Orthop 2017:4:33.

14 Tofte JN, Holte AJ, Noiseux N. Popliteal (baker's) cysts in the setting of primary knee arthroplasty. lowa Orthop J 2017;37:177-80.

15 Janzen DL, Peterfy CG, Forbes JR, et al. Cystic lesions around the knee joint: MR imaging findings. AJR Am J Roentgenol 1994;163:155-61.

16 Chiou CS, Liao ST, Liu HY, et al. Prevalence of Baker's cysts in painful primary osteoarthritis of the knee: a musculoskeletal ultrasound study. Formosan Journal of Rheumatology 2008;22:43-9.

Copyright 2018 BMJ Publishing Group. All rights reserved. For permission to reuse any of this content visit

http://group.bmj.com/group/rights-licensing/permissions.

BMJ Case Report Fellows may re-use this article for personal use and teaching without any further permission.

Become a Fellow of BMJ Case Reports today and you can:

- Submit as many cases as you like

- Enjoy fast sympathetic peer review and rapid publication of accepted articles

- Access all the published articles

Re-use any of the published material for personal use and teaching without further permission

For information on Institutional Fellowships contact consortiasales@bmjgroup.com

Visit casereports.bmi.com for more articles like this and to become a Fellow 